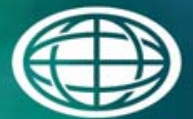

Savannah River

National Laboratory "m

OPERATED BY SAVANNAH RIVER NUCLEAR SOLUTIONS

\title{
Analysis of Out of Date MCU Modifier Located in SRNL
}

\author{
C. L Crawford
}

October 2014

SRNL-STI-2014-00420 


\section{DISCLAIMER}

This work was prepared under an agreement with and funded by the U.S. Government. Neither the U.S. Government or its employees, nor any of its contractors, subcontractors or their employees, makes any express or implied:

1. warranty or assumes any legal liability for the accuracy, completeness, or for the use or results of such use of any information, product, or process disclosed; or

2. representation that such use or results of such use would not infringe privately owned rights; or

3. endorsement or recommendation of any specifically identified commercial product, process, or service.

Any views and opinions of authors expressed in this work do not necessarily state or reflect those of the United States Government, or its contractors, or subcontractors.

\section{Printed in the United States of America}

Prepared for U.S. Department of Energy 


\section{Analysis of Out of Date MCU Modifier Located in SRNL}

C. L. Crawford

October 2014

Prepared for the U.S. Department of Energy under

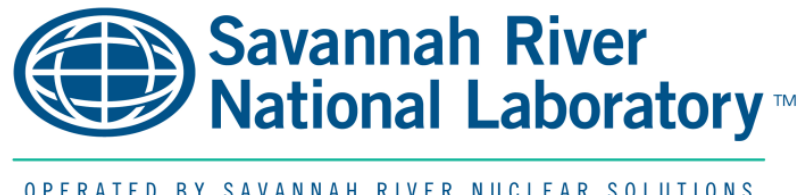
contract number DE-AC09-08SR22470. 


\section{REVIEWS AND APPROVALS}

\section{AUTHORS:}

C. L. Crawford, Process Technology Programs

Date

TECHNICAL REVIEW:

T. B. Peters, Advanced Characterization \& Process, Reviewed per E7 2.60 Date

APPROVAL:

F. M. Pennebaker, Manager

Date

Advanced Characterization \& Process

S. L. Marra, Manager

Date

Environmental \& Chemical Process Technology Research Programs

D. J. Martin, Manager

Date

Treatment Processes Engineering 
SRNL-STI-2014-00420

Revision 0

\section{LIST OF REVISIONS}

\begin{tabular}{|l|l|l|l|}
\hline $\begin{array}{l}\text { Revision } \\
\text { Number }\end{array}$ & Summary of Changes & Date \\
\hline \hline None-Initial Issue & & October 2014 \\
\hline & & & \\
\hline & & & \\
\hline
\end{tabular}




\section{EXECUTIVE SUMMARY}

SRNL recently completed density measurements and chemical analyses on modifier samples stored in drums within SRNL. The modifier samples date back to 2008 and are in various quantities up to 40 gallons. Vendor information on the original samples indicates a shelf life of 5 years. There is interest in determining if samples that have been stored for more than the 5 year shelf life are still acceptable for use. The Modular Caustic Side Solvent Extraction Unit (MCU) Solvent component Cs-7SB [(2,2,3,3tetraflouropropoxy)-3-(4-sec-butylphenoxy)-2-propanol, CAS \#308362-88-1] is used as a diluent modifier to increase extractant solubility and provide physical characteristics necessary for diluent trimming.

Current analyses results indicate the following:

- Density measurements indicate that this salient physical characteristic of the modifier samples is the same regardless of the age of the samples that originated over the time period from 2008 through 2011. An average density from the modifier samples is determined to be $1.19 \mathrm{~g} / \mathrm{mL}$ and is about $4 \%$ higher than an assumed $1.14 \mathrm{~g} / \mathrm{mL}$ density used in next generation solvent preparation within SRNL.

- Chemical analyses also show highly consistent results between the four samples suggesting no significant changes have occurred in the modifier samples over time.

- The HPLC results reveal that these modifier samples are all analyzed to be in the range of 96.9 to $100 \%$ wt. $\%$ modifier with no detectable impurities $>0.008$ wt. $\%$.

- The SVOA results show that each sample is $>98$ wt.\% modifier with no detectable impurities $>0.1$ wt. $\%$.

- Both NMR and FTIR results suggest that all the various aged drum modifier samples are very similar and they all compare very well with a current modifier sample analysis.

- The total concentration of impurities based on the combined HPLC and SVOA results fall within the procurement specification.

SRNL recommends that these modifier drums can continue to be used as MCU solvent components for next generation solvent preparation. All of the modifier analyses from the drums dating from 2008 through 2011 appear to be acceptable for continued use, which suggest that the 5 year shelf life may be too restrictive. SRNL recommends continuing analyses of the various modifier drums on an annual basis as each drum exceeds the original 5 year shelf life time period. SRNL also recommends that SRR develop a utilization strategy for these modifier samples based on the results of this report. 


\section{TABLE OF CONTENTS}

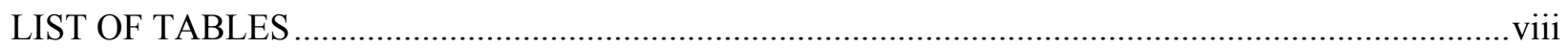

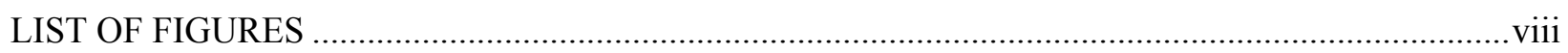

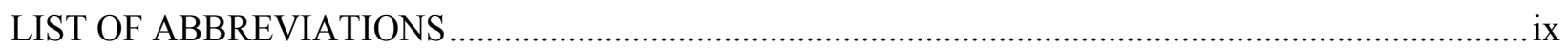

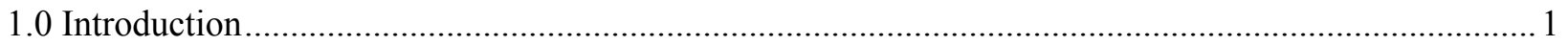

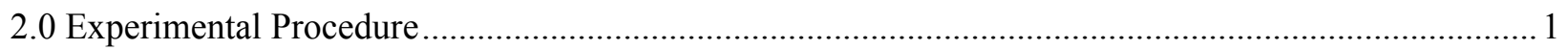

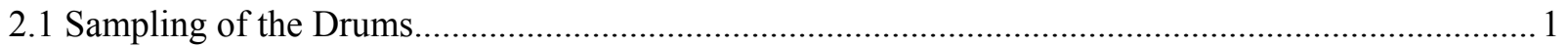

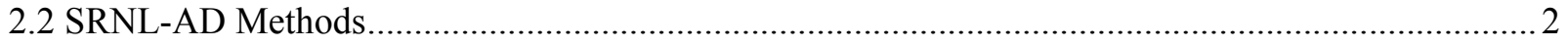

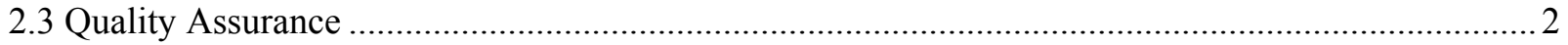

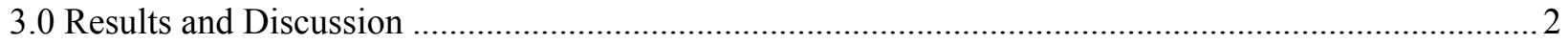

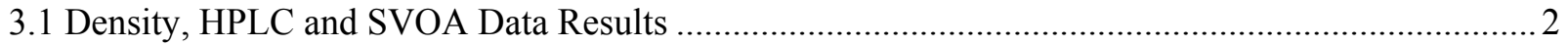

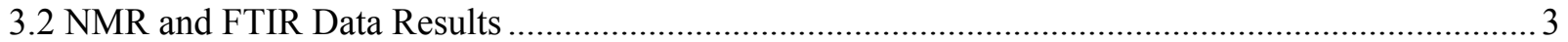

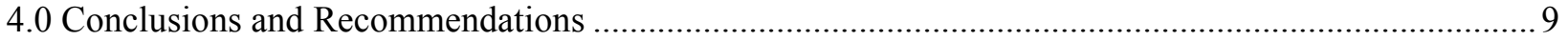

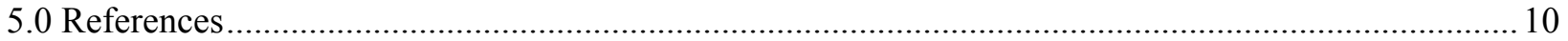




\section{LIST OF TABLES}

Table 2-1. Drum Sample Identifications and Analyses Performed............................................................ 2

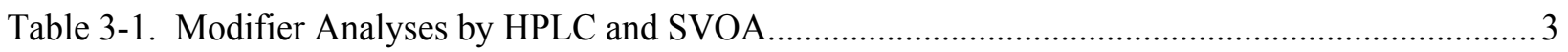

\section{LIST OF FIGURES}

Figure 1. NMR Results, Intensity vs. Proton ppm shift from TMS in $10-0$ Range .............................. 4

Figure 2. Marshallton COA NMR Proton ppm Shift from TMS in 7.0 to 1.0 Range............................... 5

Figure 3. NMR Results, Intensity vs. ${ }^{13} \mathrm{C}$ ppm Shift from TMS in $160-10$ Range................................. 6

Figure 4. Marshallton COA NMR ${ }^{13} \mathrm{C}$ ppm Shift from TMS in 160 to 10 Range ................................... 7

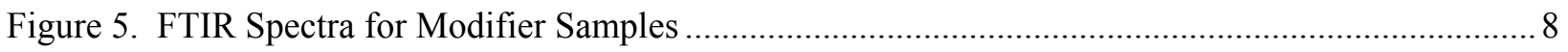




\section{LIST OF ABBREVIATIONS}

$\begin{array}{ll}\text { AD } & \text { Analytical Development } \\ \text { COA } & \text { Certificate of Analysis } \\ \text { CSSX } & \text { Caustic Side Solvent Extraction } \\ \text { E\&CPT } & \text { Environmental and Chemical Process Technology } \\ \text { FTIR } & \text { Fourier Transform Infrared } \\ \text { HPLC } & \text { High Performance Liquid Chromatography } \\ \text { MCU } & \text { Modular Caustic Side Solvent Extraction Unit } \\ \text { NMR } & \text { Nuclear Magnetic Resonance } \\ \text { SRNL } & \text { Savannah River National Laboratory } \\ \text { SRR } & \text { Savannah River Remediation } \\ \text { SVOA } & \text { Semi Volatile Organic Analysis } \\ \text { TMS } & \text { Tetramethylsilane } \\ \text { TTR } & \text { Technical Task Request }\end{array}$




\subsection{Introduction}

The Savannah River National Laboratory (SRNL) currently has stored quantities of Modular Caustic Side Solvent Extraction Unit (MCU) Solvent component Cs-7SB [(2,2,3,3tetraflouropropoxy)-3-(4-sec-butylphenoxy)-2-propanol, CAS \#308362-88-1], which is used as a diluent modifier to increase extractant solubility and provide physical characteristics necessary for diluent trimming. The several drums of modifier currently in SRNL storage have passed their expiration date of 5 years (or are approaching the 5 year expiration), and Savannah River Remediation (SRR) has tasked SRNL with determining the salient physical characteristics of the modifier necessary for acceptable use, and the current chemical state of the modifier on hand via a Technical Task Request (TTR). ${ }^{1}$ Original information specifying the 5 year shelf life and various analyses of the modifier from 2008 are available from the Marshallton Research Laboratories Certificate of Analysis (COA). ${ }^{2}$ A detailed description of the main structural isomer (1-(2,2,3,3-tetrafluoropropoxy)-3-(4-sec-butylphenoxy)-2-propanol) and the minor structural isomer (2-(4-sec-butylphenoxy)-3-(2,2,3,3-tetrafluoropropoxy)-1-propanol) and various impurities associated with the Caustic Side Solvent Extraction (CSSX) solvent components can be found in Reference 3. This work is governed by a Task Technical and Quality Assurance Plan. ${ }^{4}$ Characterization of the modifier samples currently stored in SRNL is complete and documented in this report.

\subsection{Experimental Procedure}

\subsection{Sampling of the Drums}

Modifier samples were obtained using established protocols involving acetone-cleaned glassware as described E\&CPT L29 procedure, 'Next Generation Solvent Preparation'.5 A glass caliwasa tube sampler was used to obtain a sample from each drum that was submitted for analysis in a clean glass sample bottle fitted with a Teflon-lined lid. The caliwasa sampling tube was rinsed with acetone and cleaned in between each drum sample. Densities of the modifier samples were estimated from weighing a $50 \mathrm{~mL}$ sample in a $50 \mathrm{~mL}$ volumetric flask on a calibrated three-place balance. These density measurements obtained at nominal ambient temperature of $\sim 23{ }^{\circ} \mathrm{C}$ were obtained as the drums were being sampled. Analysis of the modifier samples was performed by the SRNL Analytical Development (AD) section for both High Performance Liquid Chromatography (HPLC) and Semi Volatile Organic Analysis (SVOA). These analyses were performed on diluted samples of the as-received modifier. Personnel within the Environmental \& Chemical Process Technology (E\&CPT) Separations and Actinide Science group performed the

Nuclear Magnetic Resonance (NMR) and the Fourier Transform Infrared Spectroscopy (FTIR) on pure, undiluted modifier samples. These methods are aimed at characterizing the modifier samples as described below.

HPLC- Qualitative and quantitative analyses of organic compounds, especially thermally unstable ones.

SVOA- Quantitative organics analysis for samples containing high boiling analytes.

NMR- Detects isomerization of the modifier (movement of $\mathrm{OH}-$ and change in architecture). 
FTIR- Useful in determining structure and functional groups present in pure organic materials.

The Marshallton $\mathrm{COA}^{2}$ indicates that the modifier matrix as determined by gas chromatographic analysis is $>96 \%$ main structural isomer, $<1-2 \%$ of a minor structural isomer, $<0.05 \% 4-\mathrm{Sec}-$ butylphenol and $<2 \%$ of all other epoxide addition side products and polymers after initial makeup.

\subsection{SRNL-AD Methods}

Given in Table 2-1 are the sample identifications and the SRNL-AD methods used for characterization.

Table 2-1. Drum Sample Identifications and Analyses Performed

\begin{tabular}{|c|c|c|c|c|c|c|}
\hline \multirow{2}{*}{ Sample } & \multirow{2}{*}{$\begin{array}{c}\text { QTY } \\
\text { (Approximate } \\
\text { Gallons) }\end{array}$} & \multicolumn{5}{|c|}{ Analysis } \\
\cline { 4 - 7 } & & HPLC* & SVOA* & NMR** & FTIR** & Density*** \\
\hline Drum 1 MOD2008-M-1 & 30 & $\mathrm{X}$ & $\mathrm{X}$ & $\mathrm{X}$ & $\mathrm{X}$ & $\mathrm{X}$ \\
\hline Drum 2 MOD2010-M-2 & 40 & $\mathrm{X}$ & $\mathrm{X}$ & $\mathrm{X}$ & $\mathrm{X}$ & $\mathrm{X}$ \\
\hline Drum 3 MOD2010-M-3 & 40 & $\mathrm{X}$ & $\mathrm{X}$ & $\mathrm{X}$ & $\mathrm{X}$ & $\mathrm{X}$ \\
\hline Drum 4 MOD2011-M-3 & 20 & $\mathrm{X}$ & $\mathrm{X}$ & $\mathrm{X}$ & $\mathrm{X}$ & $\mathrm{X}$ \\
\hline
\end{tabular}

* Analyses performed by AD

** Analyses performed by E\&CPT, Separations \& Actinide Science personnel

*** Density performed by E\&CPT, Advanced Characterization \& Process personnel

\subsection{Quality Assurance}

Requirements for performing reviews of technical reports and the extent of review are established in manual E7 2.60. SRNL documents the extent and type of review using the SRNL Technical Report Design Checklist contained in WSRC-IM-2002-00011, Rev. 2.

\subsection{Results and Discussion}

\subsection{Density, HPLC and SVOA Data Results}

Presented in Table 3-1 are the density, HPLC and SVOA results for the modifier samples from each of the four different drums. These results show that all four modifier samples are very similar to each other. The measured densities are about $4 \%$ higher than the 'approximate density at $20^{\circ} \mathrm{C}$ ' cited in Reference 5. The HPLC analyses indicate that all the analyzed modifier samples were 96.9 to $100 \%$ wt.\% modifier. No unexpected peaks were observed in the HPLC analyses. The expected HPLC detection limit for 4-Sec-butyphenol and other impurities is $\sim 100$ $\mathrm{mg} / \mathrm{L}$, or $\sim 0.008 \mathrm{wt} . \%$ given the measured modifier density. All SVOA results indicate that the modifier samples are $>98$ wt.\% modifier and no impurities were detected above the method detection limit of $0.1 \mathrm{wt} . \%$. 
SRNL-STI-2014-00420

Revision 0

Table 3-1. Modifier Analyses by HPLC and SVOA

\begin{tabular}{|c|c|c|c|c|}
\hline Sample & Analyte & Density & HPLC* & SVOA* \\
\hline & & $(\mathrm{g} / \mathrm{mL})$ & $($ wt. $\%)$ & (wt. $\%)$ \\
\hline Drum 1 MOD2008-M-1 & Modifier & 1.19 & 96.9 & $>98$ \\
\hline Drum 2 MOD2009-M-2 & Modifier & 1.19 & 97.8 & $>98$ \\
\hline Drum 3 MOD2010-M-3 & Modifier & 1.18 & 100 & $>98$ \\
\hline Drum 4 MOD2011-M-4 & Modifier & 1.19 & 98.0 & $>98$ \\
\hline
\end{tabular}

* No impurities were identified from either HPLC or SVOA analyses

\subsection{NMR and FTIR Data Results}

NMR results for the modifier samples from the four drums are shown in Figure 1 for the proton ppm shift from tetramethylsilane (TMS) in $10-0$ ppm range and a comparative NMR spectra from the Marshallton COA is shown in Figure 2 for the proton ppm shift from TMS in the 7.0 to $1.0 \mathrm{ppm}$ range. Figure 2 information to the right of the Marshallton NMR spectra indicates that the modifier was diluted in deuteriochloroform, $\mathrm{CDCl}_{3}$, a common diluent for NMR analysis. The NMR spectra in Figure 1 are also referenced to a standard sample from Marshallton shown as the bottom trace for this figure. The standard modifier sample used is a laboratory sample known to be within the five year shelf life specification. Figure 1 shows that all the drum samples are similar based on comparison of all the major peaks. The various chemical shift peaks from the four analyzed samples also align very well with the standard. Some trace peaks associated with water appearing at $2 \mathrm{ppm}$ are visible in the drum sample data. These peaks are not visible in either the standard sample (bottom trace of Figure 1) nor the Marshallton COA NMR spectra of Figure 2.

NMR results for the modifier samples from the four drums are shown in Figure 3 for the ${ }^{13} \mathrm{C}$ ppm shift from TMS in the $160-10 \mathrm{ppm}$ range. Comparative NMR spectra from the Marshallton $\mathrm{COA}$ is shown in Figure 4 for the ${ }^{13} \mathrm{C}$ shift from TMS in the 160 to $10 \mathrm{ppm}$ range. Information in Figure 4 also indicates that the Marshallton ${ }^{13} \mathrm{C}$ NMR used $\mathrm{CDCl}_{3}$ as diluent.

Figure 3 shows also that all the drum samples are similar based on comparison of all the major peaks. The various chemical shift peaks from the four analyzed samples align very well with the standard. A few trace peaks for the drum 1 sample are indicated as aromatic impurities in the range of 150 to $160 \mathrm{ppm}$. Very small trace peaks for the drum 2 sample are indicated as cyclohexane just below $30 \mathrm{ppm}$. None of these trace peaks in the range of 150 to $160 \mathrm{ppm}$ or below $30 \mathrm{ppm}$ are observed in the bottom standard trace of Figure 3. However it should be noted that similar trace peaks at 150 and $160 \mathrm{ppm}$ are visible in the Marshallton COA NMR spectra of Figure 4. This indicates that the aromatic impurities identified in the drum 1 sample trace of Figure 3 are those expected from the original modifier matrix, i.e., resulting from the synthesis of the modifier, and are not associated with storage of the material since 2008 in SRNL. SRNL personnel are unaware of any tests relating the impact of cyclohexane to the performance of the modifier. However, it is unlikely to have any detrimental impact other than to dilute the solvent. 


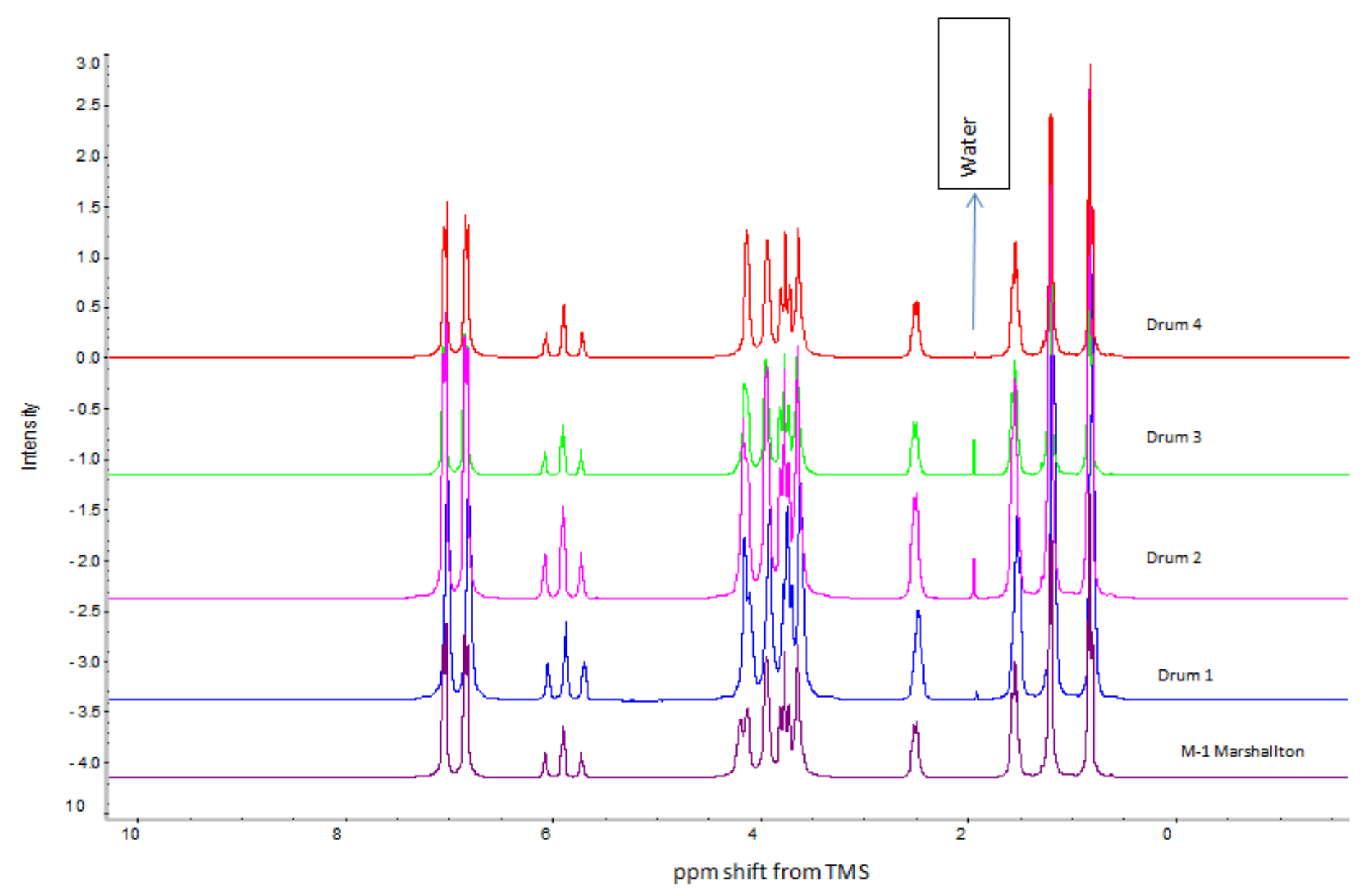

Figure 1. NMR Results, Intensity vs. Proton ppm shift from TMS in 10 - 0 Range 


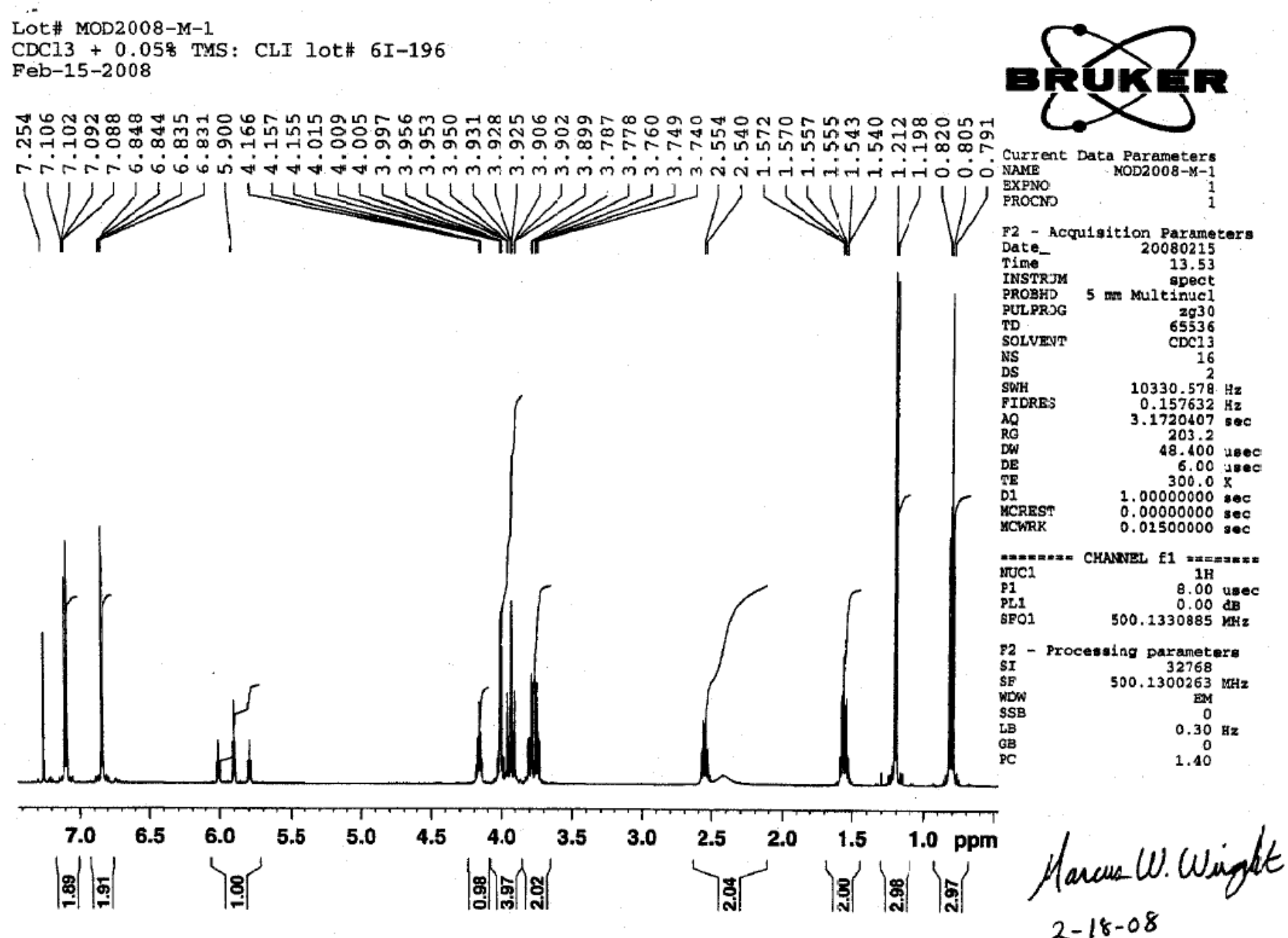

Figure 2. Marshallton COA NMR Proton ppm Shift from TMS in 7.0 to 1.0 Range 


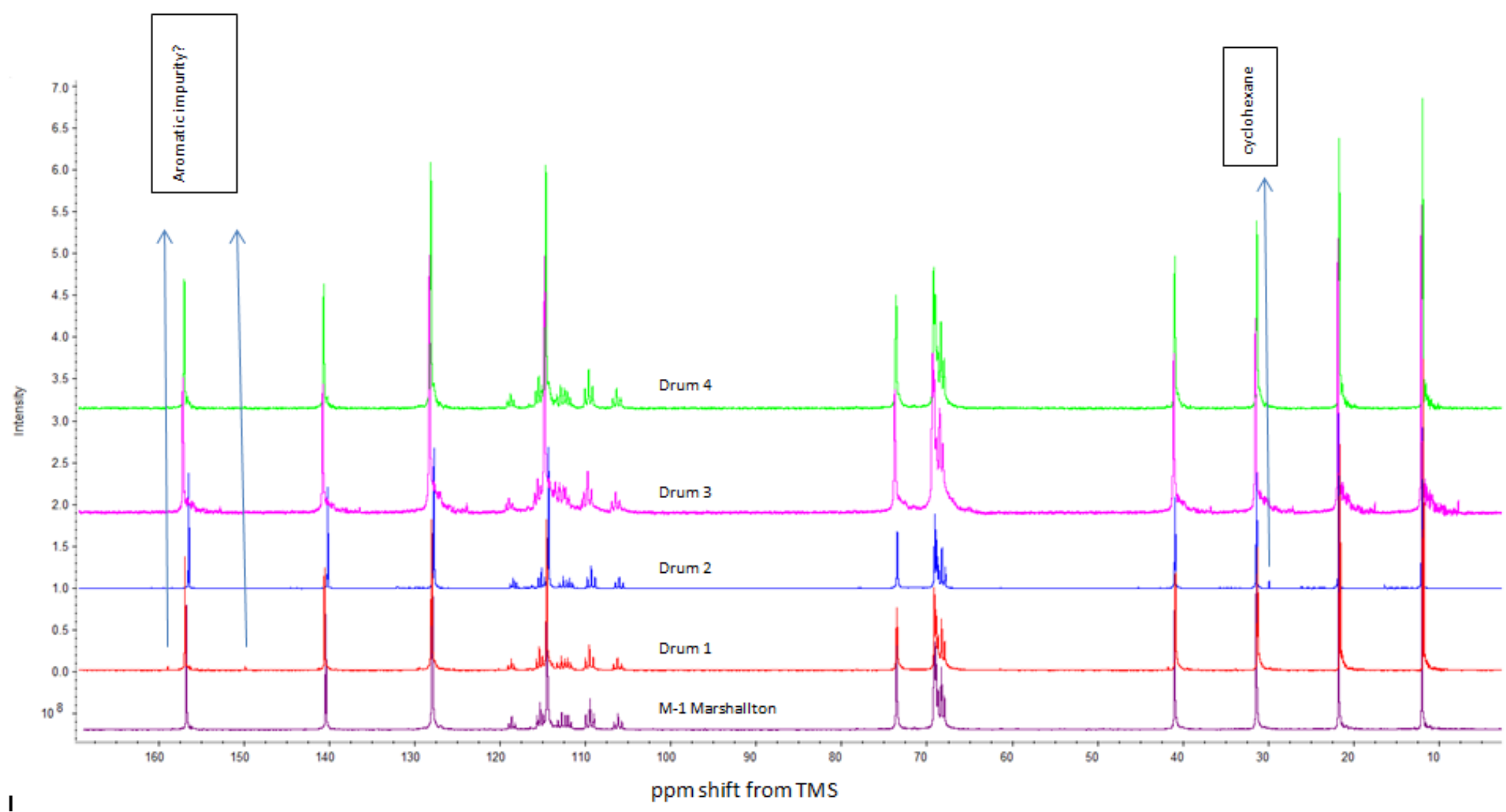

Figure 3. NMR Results, Intensity vs. ${ }^{13} \mathrm{C}$ ppm Shift from TMS in $160-10$ Range 


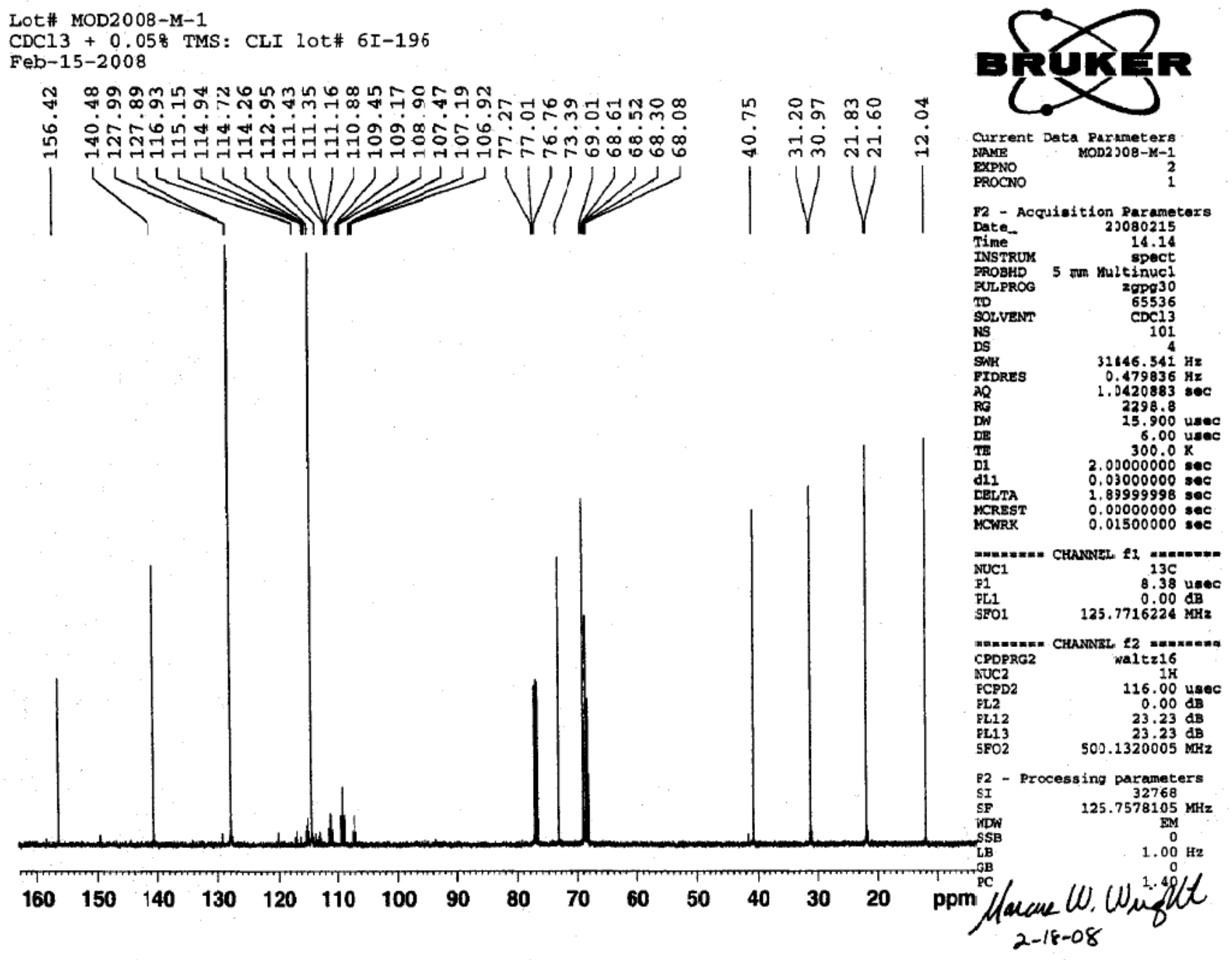

Figure 4. Marshallton COA NMR ${ }^{13} \mathrm{C}$ ppm Shift from TMS in 160 to 10 Range 
Figure 5 FTIR data show that all the drum samples have similar structure and functional groups as evidenced by the similar spectroscopic peaks at the various wavenumbers between $3,000 \mathrm{~cm}^{-1}$ and $500 \mathrm{~cm}^{-1}$. These spectra also match very well to the standard modifier sample shown as the bottom trace.

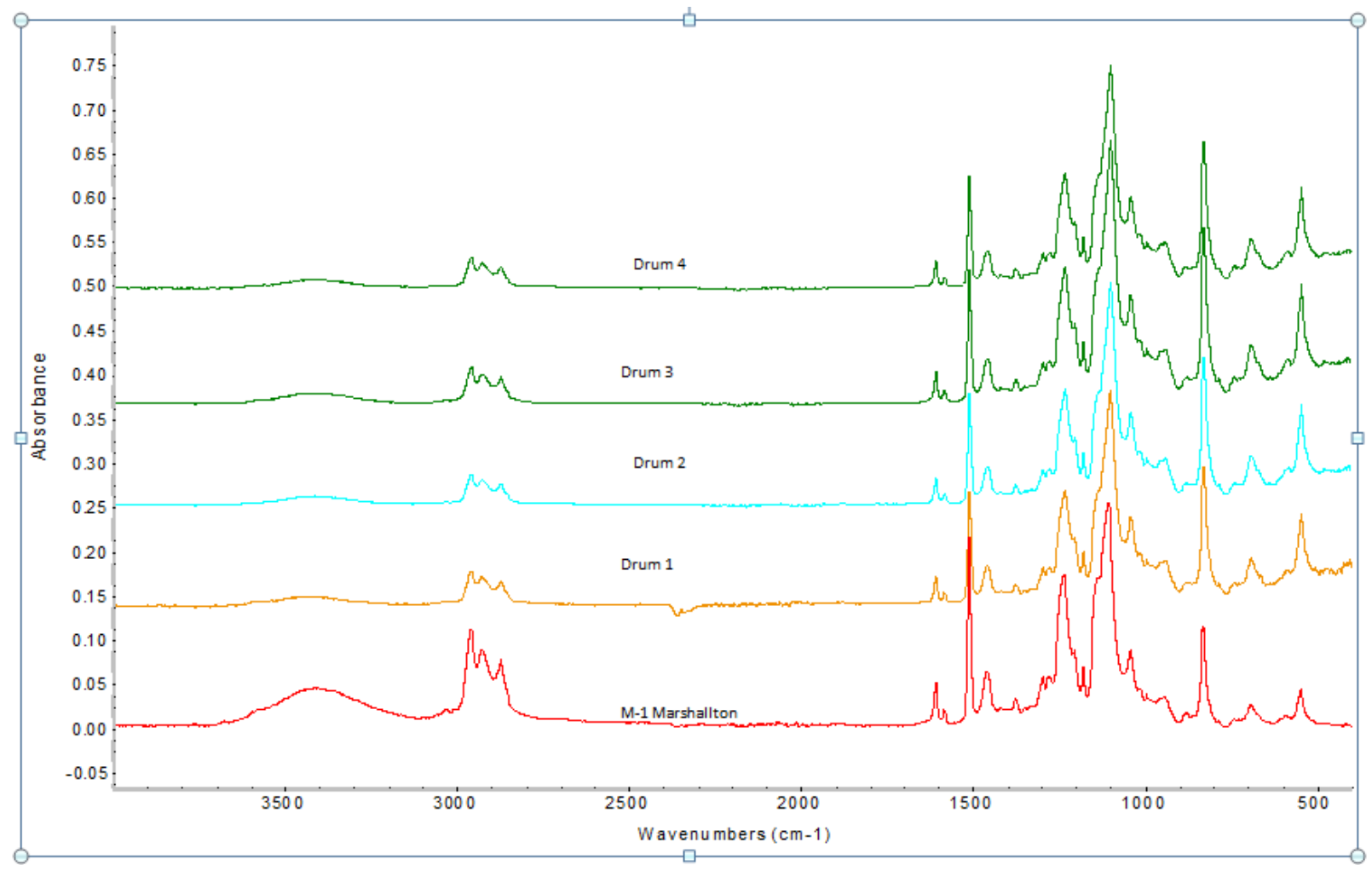

Figure 5. FTIR Spectra for Modifier Samples 
SRNL-STI-2014-00420

Revision 0

\subsection{Conclusions and Recommendations}

Analyses performed to determine the current chemical state of four different dated modifier drum samples indicate that no significant decomposition or degradation has occurred.

- Density measurements indicate that this salient physical characteristic of the modifier samples is the same regardless of the age of the samples that originated over the time period from 2008 through 2011. An average density from the modifier samples is determined to be $1.19 \mathrm{~g} / \mathrm{mL}$ and is about $4 \%$ higher than an assumed $1.14 \mathrm{~g} / \mathrm{mL}$ density used in next generation solvent preparation within SRNL.

- Chemical analyses also show highly consistent results between the four samples suggesting no significant changes have occurred in the modifier samples over time.

- The HPLC results reveal that these modifier samples are all analyzed to be in the range of 96.9 to $100 \%$ wt. $\%$ modifier with no detectable impurities $>0.008$ wt. $\%$.

- The SVOA results show that each sample is $>98$ wt.\% modifier with no detectable impurities $>0.1$ wt. $\%$.

- Both NMR and FTIR results suggest that all the various aged drum modifier samples are very similar and they all compare very well with a current modifier sample analysis.

- The total concentration of impurities based on the combined HPLC and SVOA results fall within the procurement specification. ${ }^{2}$

SRNL recommends that these modifier drums can continue to be used as MCU solvent components for next generation solvent preparation. All of the modifier analyses from the drums dating from 2008 through 2011 appear to be acceptable for continued use, which suggest that the 5 year shelf life may be too restrictive. SRNL recommends continuing analysis of the various modifier drums on an annual basis as each drum exceeds the original 5 year shelf life time period. SRNL also recommends that SRR develop a utilization strategy for these modifier samples based on the results of this report. 


\subsection{References}

1) X-TTR-H-00039, Liquid Waste Technical Task Request, 'Analyzing the contents of the outof-date Modifier Drums', Rev. 2 (2014)

2) Test and Certification Data, Purchase Order AC61974, Marshalltown Research Labs Incorporated, February 2008.

3) P. V. Bonnesen, 'Letter Report on Minimum Purity Requirements and Product Specifications for CSSX Solvent Components', Letter Report: CERS/SR/SX/007, September 21, 2000.

4) C. L. Crawford and M. L. Restivo, 'Task Technical and Quality Assurance Plan for Analysis of Out of Date MCU Modifier Located in SRNL', SRNL-RP-2014-00470, June 2014.

5) E\&CPT Manual L29, Procedure ITS-173, 'Next Generation Solvent Preparation', latest revision. 


\section{Distribution:}

S. L. Marra, 773-A

T. B. Brown, 773-A

D. H. McGuire, 999-W

S. D. Fink, 773-A

C. C. Herman, 773-A

E. N. Hoffman, 999-W

F. M. Pennebaker, 773-42A

W. R. Wilmarth, 773-A

T. B. Peters, 773-42A

M.R. Williams, 786-5A

M. L. Restivo, 773-42A

F. Fondeur, 773-A

Records Administration (EDWS)

E. A. Brass, $241-121 \mathrm{H}$

C. K. Chiu, 704-27S

E. J. Freed, 704-S

A. G. Garrison, $241-121 \mathrm{H}$

B. A. Gifford, 704-56H

D. J. Martin, 241-152H

A. R. Shafer, $766-\mathrm{H}$

T.E. Smith, 241-152H

R. T. McNew 241-152H
P. R. Jackson, DOE-SR, 703-46A

J. A. Crenshaw, 703-46A 